\title{
Oro-facial and dental injuries in club rugby union players
}

\author{
E. J. Kay FDS, P. Kakarla MPH, D. A. D. Macleod FRCS and T. P. L. McGlashan BDS \\ Department of Public Health, University of Glasgow, Scotland
}

\begin{abstract}
Oro-facial and dental injuries are of particular importance as dental tissues have a low potential for recovery when damaged and such injuries can give rise to functional, aesthetic and psychological disfigurement. Also their repair can be costly, distressing and time consuming. This study sought to clarify the nature and severity of oro-facial injuries amongst rugby players in a first division club in Scotland. A secondary aim of the study was to examine the influence of position and standard of play on injury rates. The results show that oro-facial injuries are common amongst rugby players, and that players in the first fifteen were at the greatest risk. Although injuries may still occur when mouthguards are used, their severity will be reduced by use of such protective devices.
\end{abstract}

Keywords: Oro-facial injury, dental injury, rugby, mouthguards

Oro-facial injuries are commonly sustained by players of contact sports ${ }^{1}$. If all different sports are considered together, the commonest site of damage is the lower limbs ${ }^{2}$. However, in rugby the face is the commonest part of the body to be injured. The term 'oro-facial' damage includes a wide range of injuries, but dental injuries (damage to the teeth and supporting tissues) are said to be the most common type of oro-facial injury sustained by sports players ${ }^{3}$.

One-third of all people suffering from dental trauma do so during participation in sports activities, and although such injuries may happen in any sport, they are clearly more prevalent amongst those participating in the more vigorous and competitive contact sports ${ }^{4}$.

Dental injuries are of particular importance for several reasons. First, the exposure of a dental nerve such as that which occurs when a tooth is fractured, is painful and distressing. Secondly, dental injuries pose particularly difficult treatment problems for the dentist and therefore it is costly to repair dentition to a functional and aesthetic condition. Thirdly, repeated injuries and subsequent treatments may well influence the players' attitude to his game. Lastly, and of greatest importance, dental tissues have an almost non-existent capacity for recovery. Any part of

Address for correspondence: E. J. Kay, Department of Public Health, University of Glasgow, Glasgow G12 8QQ, Scotland, UK

(C) 1990 Butterworth-Heinemann Ltd 0306-3674/90/040271-03 the dentition which is lost through trauma can only be replaced by prostheses and restorations, unlike the limbs.

Figure 1 shows a radiograph of a 26-year-old rugby player's dentition as an example of the extensive damage to dentition which can occur. All the anterior teeth have been replaced by porcelain crowns with metal posts and cores. Two of these teeth have required apicectomies (exposure and curretage of the apex of the tooth root). The posterior teeth have required gold-shell crowns due to repeated impacts on a heavily filled dentition.

It is clear that oro-facial and dental injuries and their prevention are important to all involved in sports and sports medicine, and will become more so with the increasing popularity of contact sports. As dental caries in the younger cohorts of the population declines, dental injuries will become a proportionately greater cause of problems, particularly in children who have never experienced operative dental care. The prevention of dental injuries in school children is therefore crucial.

The aim of the study reported here was to assess the nature and severity of oro-facial injuries amongst Scottish first division club rugby players. It also aimed to examine the effect of player experience, team position, team level and mouthguard use, on injury rates.

\section{Method}

One first division Scottish rugby club was selected for inclusion in this study. All of the 99 players known to the club secretary were forwarded a questionnaire along with a covering letter from the Scottish Rugby

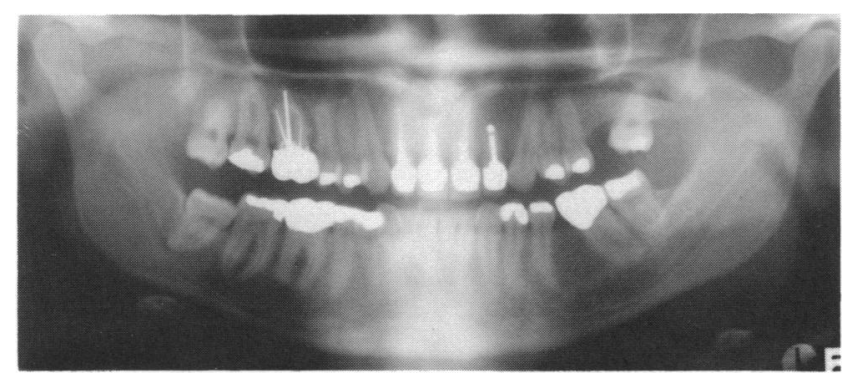

Figure 1. Radiograph of rugby player's dentition showing extensive repair 
Union's medical and dental advisors, and a replypaid envelope. Non-respondents were telephoned 2 weeks subsequent to the initial mailing in order to stimulate further response. The questionnaire, which had been previously tested and validated in pilot studies, asked players about their rugby careers and for details of any oro-facial injuries sustained during participation in the sport. Questions concerning dental work carried out as a result of rugby injuries were also included. Finally, the players were asked about their use of mouthguards and their reasons for failing to avail themselves of this readily available protection.

\section{Results}

Sixty-four percent (63) of the players returned questionnaires. The average length of time the players had been participating in rugby on a regular basis was 15 years, and the age range of the players was between 14 and 40 years (average 26.1).

Soft tissue injuries were common. Forty percent (25) of the participants had, at some time during their rugby careers, required sutures in either their face or head. Table 1 shows that skeletal and dental injuries were even more prevalent. Forty-four percent (28) of the respondents had at some time suffered a significant nasal injury to bone or cartilage - 'a broken nose'. Thirty percent (19) had fractured their teeth, and $19 \%(12)$ had had teeth completely knocked out. Five percent (three) had fractured their mandibles. The overall average injury rate per player was therefore 0.98 .

Table 2 shows that some playing positions on the field increase the likelihood of oro-facial injury and,

Table 1. Number of players experiencing hard tissue injury

\begin{tabular}{lcc}
\hline & $N$ & $\begin{array}{c}\text { Percentage } \\
\text { of all } \\
\text { respondents }\end{array}$ \\
\hline Fractured nasal bones/cartilage & 28 & 44 \\
Fractured teeth & 19 & 30 \\
Avulsed teeth & 12 & 19 \\
Fractured mandibles & 3 & 5 \\
\hline
\end{tabular}

Average number of injuries per player $=0.98$

Table 2. Effect of field position on rates of oro-facial injury

\begin{tabular}{lccc}
\hline & $\begin{array}{c}\text { No. of } \\
\text { players }\end{array}$ & $\begin{array}{c}\text { No. of } \\
\text { injuries }\end{array}$ & $\begin{array}{c}\text { Injury rate } \\
\text { per player }\end{array}$ \\
\hline Prop & 18 & 6 & 0.33 \\
Hooker & 3 & 3 & 1.0 \\
2nd row & 6 & 3 & 0.5 \\
Wing forward & 13 & 17 & 1.3 \\
Locks & 5 & 7 & 1.4 \\
Scrum half & 4 & 5 & 1.3 \\
Stand-off & 4 & 6 & 1.5 \\
Centre & 8 & 9 & 1.1 \\
Wing & 9 & 5 & 0.6 \\
Full back & 1 & 1 & 1.0 \\
Total & 63 & 62 & \\
\hline
\end{tabular}

Table 3. Rates of oro-facial injuries reported at each team level

\begin{tabular}{lccc}
\hline Team & $\begin{array}{c}\text { No. of } \\
\text { players }\end{array}$ & $\begin{array}{c}\text { No. of } \\
\text { injuries }\end{array}$ & $\begin{array}{c}\text { Injury rate } \\
\text { per player }\end{array}$ \\
\hline 1st & 18 & 23 & 1.3 \\
2nd & 20 & 20 & 1.0 \\
3rd & 19 & 18 & 0.95 \\
4th & 3 & 0 & 0 \\
5th & 3 & 1 & 0.33 \\
Total & 63 & 62 & 0.98 \\
\hline
\end{tabular}

also, those playing in the higher level teams appeared to be more prone to dental and facial injuries (Table 3). Among the dental injuries, all but two of the teeth which had been fractured or avulsed were anterior teeth and the majority $(90 \%)$ were from the maxillary arch. Injuries to teeth on the left side were reported twice as commonly as those on the right. A total of $43 \%$ (27) of the participants claimed that they had some type of dental prosthesis (crowns, bridges or dentures) which had been required solely due to rugby injuries.

Sixty-three percent (40) of the respondents reported that they now regularly wore a mouthguard while playing rugby. The majority of these $(66 \%)$ were custom made by dentists, rather than being shop bought. Table 4 shows the reasons given by the players for ever failing to wear mouthguards.

\section{Discussion}

This study was retrospective and observational in nature. As with any retrospective study, reporting bias is problematic, as the questionnaire was asking players to cast their minds back to injuries which may have occurred many years previously. Similarly, the small sample size and the fact that the sample was not randomly selected may affect the results. However, this is the first report of oro-facial injuries in adult club level rugby, and the results therefore warrant attention.

It is clear from this study that oro-facial and dental injuries are a far from rare occurrence on the rugby field. Indeed, the injury rate of 0.98 indicates that it is highly probable that anyone who participates regularly in rugby will, at some time, suffer from one of these types of injury. It is also clear that the rate of injury is much greater in those playing at the higher levels of the sport, presumably because of greater commitment to the game.

It is easy to hypothesize that the reasons for the left/right distribution of dental injuries was due to purposeful blows, but further more definitive studies are required to support this assumption.

Due to the rising cost of, and the difficulties in successfully treating dental injuries, it seems clear from this study that a mouthguard is an essential part of a rugby player's kit. Players should be advized that custom-made mouthguards offer the greatest comfort, fit, and protection against these common injuries. Use of mouthguards as a health oriented behaviour will increase if the habit of wearing them is 
promulgated and encouraged when players are young. Junior clubs and schools should insist that all young rugby players use mouthguards when participating in contact sports.

\section{Acknowledgements}

The authors wish to thank Stewarts-Melville Rugby Club for their very great cooperation in this study.

\section{References}

1 Muckle, D.S. 'Injuries in sports' (2nd edition), Wright, 1982

2 Chapman, P.J. Oro-facial injuries and use of mouthguards by the 1984 Great Britain Rugby League touring team $\mathrm{Br} J$ Sports Med 1985, 19, 34-36

3 Chapman, P.J. Mouthguards and the role of sporting team dentists Aust Dent J 1989, 34, 36-43

4 Weightman, D. and Browne, R.C. Injuries in eleven selected sports $\mathrm{Br} J$ Sports Med 1975, 9, 136-40

\section{The London Hospital Medical College University of London, Turner Street, London E1 2AD Tel: 071-377 7000}

The following were successful in gaining the DIPLOMA IN SPORTS MEDICINE in the 1989/90 Academic Year:

Dr Caroline Bealing

Dr Stephen Bentley

Dr Jean-Pierre Best

Dr Michael Boland

Dr Henare Broughton

Dr Sergio Correa

Dr Sharron Flahive

Dr Faith Gardner

Dr Amoni Green

Dr Roderick Jaques

Dr Gordon Mackay

Dr Conor O'Brien

Dr Ian Rapson

Dr Deborah Robinson

Dr Christopher Rufford

Dr Joyce Woffindin
PASS

PASS (with distinction)

PASS (with merit)

PASS (with merit)

PASS

PASS

PASS

PASS

PASS

PASS (with distinction)

PASS

PASS

PASS (with merit)

PASS (with merit)

PASS

PASS 